\title{
Efeito do Estádio Vegetativo do Sorgo (Sorghum bicolor, (L.) Moench) sobre a Composição Química da Silagem, Consumo, Produção e Teor de Gordura do Leite para Vacas em lactação, em Comparação à Silagem de Milho (Zea mays (L.))
}

\section{Argélia Maria Araújo Dias ${ }^{2}$, Ângela Maria Vieira Batista ${ }^{3}$, Marcelo de Andrade Ferreira ${ }^{3}$, Mário de Andrade Lira ${ }^{4}$, Ivan Barbosa Machado Sampaio ${ }^{5}$}

\begin{abstract}
RESUMO - Este trabalho foi conduzido com o objetivo de avaliar o efeito do estádio de maturação do sorgo sobre a composição química da silagem, o consumo, a produção e o teor de gordura do leite em vacas holandesas, em comparação à silagem de milho. $\mathrm{O}$ experimento foi realizado na estação experimental da Empresa Pernambucana de Pesquisa Agropecuária - IPA, localizada em São Bento do Una-PE. Foram utilizadas nove vacas holandesas puras, em fase de lactação, distribuídas em três quadrados latinos. Os quadrados foram formados de acordo com a produção de leite e a ordem de lactação e constavam de três vacas e três períodos. Cada período teve duração de 28 dias. Os tratamentos consistiram de: SM - silagem de milho; SSE - silagem de sorgo fase de emborrachamento; SSL - silagem de sorgo grão leitoso. Foram ainda fornecidos $25 \mathrm{Kg}$ de palma forrageira animal/dia e concentrado comercial de acordo com a produção de leite. A silagem de milho propiciou aos animais maior consumo médio de matéria seca da silagem e da dieta total. Não houve efeito significativo do estádio vegetativo do sorgo sobre o consumo de silagem. As produções de leite total e corrigida para $4 \%$ de gordura foram maiores nos animais que consumiram silagem de milho em relação aos que receberam silagem de sorgo no estádio de grão leitoso, todavia os que ingeriram silagem de sorgo na fase de emborrachamento não diferiram dos demais. Quanto ao teor de gordura do leite, não houve diferença significativa entre as silagens analisadas.
\end{abstract}

Palavras-chave: composição química, consumo, estádio de crescimento, produção de leite, silagem, sorgo

\section{Effect of the Sorghum (Sorghum bicolor, (L.) Moench) Growth Stage on the Silage Chemical Composition, Intake, Milk Production and Fat on Dairy Cattle, Compared with Corn Silage}

\begin{abstract}
This work aimed to evaluate the effect of the sorghum growth stage on the silage chemical composition, intake milk production and fat compared with corn silage to dairy cows. The experiment was carried out at the "São Bento do Una" research Stattion, from IPA, located in "São Bento do Una", Pernambuco, Brazil. Nine holstein lactating cows were distributed in three Latin squares design. The squares were formed according to milk yield and the lactating order and consisted of three cows and three periods. Each period was performed by 28 days. The following treatments were tested: CS - corn silage, SSB - sorghum silage in a boot stage and, SSM - sorghum silage in a milk grain stage in addition to $25 \mathrm{~kg}$ of spineless cactus animal/day and commercial concentrate according to milk production. The animals fed with corn silage showed the highest dry matter intake of the silage and of the total diet, when compared to those fed with sorghum silage at the two growth stage tested. There were no significant effects of the vegetative stage on sorghum silage intake. It was observed higher milk yield and $4 \%$ fat corrected milk yield for the animals that consumed corn silage compared to the animals that received sorghum silage in the milk grain stage. The cows fed with sorghum silage at the boot stage did not differ fron those fed the other two treatments. No significant differences were observed among the tested silages for the milk fat content.
\end{abstract}

Key Words: chemical composition, intake, growth stage, milk production, silage, sorghum

\section{Introdução}

Em regiões de clima semi-árido, devido à escassez de chuvas que se prolonga por vários meses do ano, existe a necessidade da utilização de alguns recursos de conservação de forragem. A ensilagem, quando realizada dentro das técnicas e padrões recomendados e pelo fato de conservar os princípios nutritivos do material ensilado, garante o fornecimento aos animais de alimento de boa qualidade durante todo o período crítico de estiagem. Em conseqüência, os custos de produção são minimizados e se mantêm

\footnotetext{
1 Trabalho realizado com apoio da CNPq/IPA/UFRPE

2 Zootecnista, aluno do Programa de Pós-Graduação em Zootecnia/UFRPE. E.mail: argeliadias@ig.com.br

3 Professores Adjuntos do DZ/UFRPE. E.mail: mcelo@yahoo.com.br

${ }^{4}$ Pesquisador do IPA. E.mail: mlira@hotlink.com.br

5 Professor Adjunto/ UFMG.
} 
os índices produtivos e reprodutivos, principalmente na exploração de bovinos leiteiros.

O milho tem sido a forrageira de maior utilização no processo de ensilagem. Entretanto, o sorgo tem se mostrado como boa opção em substituição ao milho, principalmente nas regiões de climas semi-áridos. Nestas regiões o sorgo tem sido mais explorado, devido à maior resistência a veranicos, maior produção por área e menor exigência quanto a fertilidade do solo, em relação ao milho.

A Empresa de Pesquisa Agropecuária (IPA) tem trabalhado no melhoramento do sorgo, objetivando obter variedades adaptadas ao semi-árido com elevada produtividade e resistência às principais pragas e doenças. Como resultado desse trabalho, algumas variedades têm se mostrado promissoras, dentre elas, a cultivar IPA-SF 25, a qual, além de adaptarse ao Agreste semi-árido de Pernambuco e áreas similares, apresenta elevados índices de produtividade e baixa incidência de doenças (IPA, 1993).

A qualidade e o valor nutritivo de uma silagem dependem, fundamentalmente, da cultivar utilizada, do estádio de maturação no momento do corte e da natureza do processo fermentativo o que refletirá diretamente na composição química e, conseqüentemente, no desempenho animal (VILELA, 1985; RODRIGUES et al., 1996).

O estádio de maturação em que são colhidas as forrageiras e submetidas ao processo de ensilagem, tem sido um dos fatores que mais alteram a qualidade e o valor nutritivo da silagem. Como regra geral, à medida que avança o estádio de maturação das forrageiras, principalmente nas gramíneas de variedades forrageiras, têm-se alterações na composição bromatológica das silagens, freqüentemente com aumentos dos teores de matéria seca (MS) e reduções nos de proteína bruta (BISHNOI et al., 1993; RUGGIERI et al., 1995; RODRIGUES et al., 1996).

A qualidade da forragem está estreitamente relacionada com o consumo voluntário do alimento, sua digestibilidade e eficiência com o qual os nutrientes digeridos são utilizados pelo animal(VALENTE, 1977).

O consumo de alimento pelo animal é considerado um índice de fundamental importância na avaliação do valor nutritivo dos alimentos, tendo em vista que o volume de nutrientes ingeridos e o desempenho animal dependem da quantidade e qualidade de alimentos consumidos. Segundo CRAMPTON (1957), a qualidade de uma forrageira é função de sua composição química e de seu consumo pelos animais, além da digestibilidade de seus nutrientes.

Concentração elevada da fração fibrosa do alimento reduz o consumo voluntário e, conseqüentemente, a disponibilidade de energia. Isto ocorre pelo efeito de enchimento do rúmen antes que todos os nutrientes necessários aos animais sejam ingeridos, como também pela saturação da capacidade de ruminação, o que refletirá na limitação da produção do leite. Entretanto, uma quantidade mínima de fibra é essencial para manter um balanço adequado da fermentação ruminal, prevenir depressão no teor de gordura do leite e queda do pH ruminal. É por isso que a qualidade da fibra torna-se um fator muito importante na dieta de ruminantes, particularmente de vacas em lactação (MERTENS, 1992; DIAS et al., 1997).

Assim, para que vacas de elevada produção possam atingir o máximo de ingestão de MS, com alto pico de produção, a dieta deve conter alta energia e fibra suficiente para garantir o funcionamento normal do rúmen. Isto, geralmente, corresponde a um mínimo de $28 \%$ de FDN para vacas durante as três primeiras semanas de lactação. Em épocas de elevada produção leiteira, pode-se reduzir estes níveis para $25 \%$, visando atender aos requerimentos energéticos das vacas. Todavia, no final da lactação aumentam-se os níveis de fibra para prevenir a diminuição de gordura do leite e porque menos energia é requerida para a produção de leite (TEIXEIRA, 1992).

A contribuição da silagem na produção de leite está diretamente relacionada com a qualidade do material fornecido ao animal e uma das formas de se avaliar o seu valor nutritivo é por intermédio do desempenho animal (BRANNON, 1965).

Esse trabalho teve como objetivos avaliar o efeito do estádio de maturação do sorgo sobre a composição química das silagens de sorgo, em comparação a silagem de milho, quanto ao consumo, produção e teor de gordura do leite para vacas em lactação.

\section{Material e Métodos}

Este trabalho foi executado na Estação Experimental da Empresa Pernambucana de Pesquisa Agropecuária-IPA, localizada em São Bento do UnaPE, no período de janeiro a março de 1998.

O experimento foi composto por três períodos com duração de vinte e um dias cada e intervalos de sete dias de adaptação. Foram utilizados nove animais puros da raça holandesa (PO), em fase de lactação, com peso vivo entre 550 e $650 \mathrm{~kg}$.

Rev. bras. zootec., 30(6S):2086-2092, 2001 
O delineamento experimental utilizado foi quadrado latino $(3 \times 3)$. Os animais utilizados em cada quadrado foram selecionados pela produção de leite e pelo período de lactação. Os tratamentos experimentais consistiram em: SM - silagem de milho (Dentado Composto); SSE - silagem de sorgo (IPA-SF 25) no estádio de emborrachamento; e SSL - silagem de sorgo no estádio de grão leitoso.

As silagens foram preparadas de acordo com as etapas do processo de ensilagem: Plantio, época de corte (estabelecida pelo tratamento), enchimento, compactação e vedação. Vale ressaltar que não houve nenhuma diferenciação entre as silagens durante as três últimas etapas do processo, exceto quanto ao tipo do silo que para as silagens de sorgo foram utilizados silos em superfície, enquanto a de milho silo tipo trincheira.

As dietas foram compostas por silagem de milho ou de sorgo, à vontade, palma forrageira (Opuntia ficus-indica Mill) (25 kg/animal) e concentrado comercial, de acordo com a produção de leite.

O concentrado foi fornecido diariamente, no momento das ordenhas, que foram realizadas às $5 \mathrm{e}$ às $15 \mathrm{~h}$. A quantidade ofertada foi de 1,0 $\mathrm{kg}$ para cada $3,0 \mathrm{~kg}$ de leite produzidos e para os animais com produções superiores a $20,0 \mathrm{~kg}$ foi fornecido $1,0 \mathrm{~kg}$ para cada $2,5 \mathrm{~kg}$ de leite, sendo $60 \%$ fornecido na primeira ordenha e os $40 \%$ restantes na segunda. Os ajustes no fornecimento do concentrado eram realizados semanalmente. Os ingredientes utilizados na formulação do concentrado comercial e sua representação percentual estão expressos na Tabela 1.

Os animais eram transferidos dos cercados individuais para o estábulo às $5 \mathrm{~h}$ para o recebimento de parte do concentrado e início da primeira ordenha. Após o término da ordenha retornavam aos cercados permanecendo até às $12 \mathrm{~h}$, quando voltavam ao estábulo onde recebiam individualmente $25,0 \mathrm{~kg}$ de palma forrageira (Opuntia ficus-indicus Mill), previamente pesada e picada, em cochos individuais. Neste mesmo local aguardavam até às $15 \mathrm{~h}$ para realização da segunda ordenha e recebimento da complementação do concentrado. Em seguida, os animais retornavam aos cercados onde permaneciam até o dia seguinte.

Para a determinação da produção de leite dos animais, diariamente, foram realizadas duas ordenhas mecânicas às 5 e $15 \mathrm{~h}$, acompanhadas de pesagens do leite produzido. No início da segunda quinzena de cada período experimental, foram coletadas amostras individuais de leite. Após a cole- ta, esse material era transportado para a sala de ordenha e determinado o teor de gordura, segundo o método de Gerben descrito por BEHMER (1965). Na correção do leite para $4 \%$ de gordura foi utilizada a fórmula descrita no NRC (1988).

Para a realização das análises bromatológicas dos alimentos, semanalmente, foram coletadas amostras das silagens, do concentrado e da palma forrageira. Esses materiais foram colocados em sacos plásticos, previamente identificados e congelados, e posteriormente, todo o material foi encaminhado ao Laboratório de Nutrição Animal, pertencente ao Departamento de Zootecnia-UFRPE, onde foram determinados os teores de matéria seca (MS), proteína bruta (PB), fibra em detergente neutro (FDN), matéria orgânica (MO) e energia bruta, segundo SILVA (1990).

No momento das análises laboratoriais, após descongelamento das amostras, foram coletadas de 10 amostras de cada silagem uma quantidade total de $10 \mathrm{~g}$, que após a pesagem foi realizada medição individual, com régua, e de cada partícula foi obtido um valor médio por tratamento do tamanho das partículas das silagens. Essas mesmas amostras foram utilizadas para determinar o pH das silagens segundo SILVA (1990).

Para as análises estatísticas foi realizada análise de variância e o teste Tukey $(\mathrm{P}<0,05)$ para comparações de médias. O total de 25 graus de liberdade correspondente ao valor de 27 dados menos um grau de liberdade para a média e outro para uma parcela perdida, essa que foi posteriormente estimada, pelo fato de um animal ter morrido no início do último período experimental. Para estimativa da parcela perdida usada nos cálculos das análises utilizou-se a fórmula descrita por SAMPAIO (1998).

Tabela 1 - Composição percentual dos ingredientes do concentrado na base da matéria natural

Table 1 - Percentage composition of concentrate diets ingredients as fed basis

\begin{tabular}{|c|c|}
\hline $\begin{array}{l}\text { Ingrediente } \\
\text { Ingredient }\end{array}$ & Participação (\%) \\
\hline Farelo de algodão & 49,35 \\
\hline Cottonseed meal & \\
\hline Farelo de milho & 49,25 \\
\hline Corn meal & \\
\hline Premix vitamínico & 0,03 \\
\hline Vitamin premix & \\
\hline $\begin{array}{l}\text { Sal mineral } \\
\text { Mineral salt }\end{array}$ & 1,47 \\
\hline $\begin{array}{l}\text { Mineral salt } \\
\text { Total }\end{array}$ & 100,00 \\
\hline
\end{tabular}




\section{Resultados e Discussão}

Os valores médios de $\mathrm{pH}$, tamanho da partícula (TP) das silagens e rendimentos de matéria seca (ton/ha) do milho e do sorgo no momento da colheita são apresentados na Tabela 2.

Os valores médios obtidos para $\mathrm{pH}$ nas silagens de milho e sorgo nas fases emborrachamento e grão leitoso encontram-se dentro dos limites que caracterizam uma fermentação desejável e adequada preservação do material.

Resultados semelhantes e muito próximos aos valores de $\mathrm{pH}$ destas silagens foram encontrados por VALENTE et al. (1984) e ALMEIDA et al. (1995) em diversas variedades de milho e sorgo e em diferentes estádios vegetativos, enquanto CHAVES et al. (1997) e GENRO et al. (1995) encontraram valores médios de 3,5 a 3,7.

Os menores tamanhos de partículas foram obtidos para a silagem de sorgo na fase de emborrachamento, possivelmente atribuído ao elevado teor de umidade presente nesse material (Tabela 3) em relação aos demais, o que possibilitou menores cortes pela picadeira durante o processo de enchimento do silo. Todavia, todos os valores encontrados estão dentro da faixa de 3 a $5 \mathrm{~cm}$ considerados por

Tabela 2 - Valores médios de pH e tamanho da partícula (TP) das silagens e rendimentos de matéria seca (ton/ ha) do milho e do sorgo no momento da colheita

Table 2 - Mean value of $\mathrm{pH}$ and particle size (PS) of the silages and dry matter yield (ton/ha) of sorghum and corn at the harvest moment

\begin{tabular}{lccc}
\hline $\begin{array}{l}\text { Tratamentos } \\
\text { Treatments }\end{array}$ & $\mathrm{pH}$ & $\begin{array}{c}\mathrm{TP}(\mathrm{cm}) \\
P S(\mathrm{~cm})\end{array}$ & $\begin{array}{c}\text { Rendimento } \\
{ }^{1}\end{array}$ \\
\hline $\begin{array}{l}\text { Silagem de milho } \\
\text { Corn silage }\end{array}$ & 4,0 & 4,1 & 7,26 \\
$\begin{array}{l}\text { Silagem de sorgo } \\
\text { emborrachamento }\end{array}$ & 3,8 & 1,9 & 4,68 \\
$\begin{array}{l}\text { Sorghum silage on } \\
\text { boot stage }\end{array}$ & & & \\
$\begin{array}{l}\text { Silagem sorgo } \\
\text { grão/leitoso }\end{array}$ & 3,9 & 3,6 & 9,91 \\
$\begin{array}{l}\text { Sorghum silage on } \\
\text { milk grain stage }\end{array}$ & & & \\
\hline 1 t/ha, * Dados coletados na Estação Experimental de São Bento do \\
Una/lPA
\end{tabular}

LAVEZZO (1988) como sendo o recomendado para que haja uma boa compactação do material. Quanto ao rendimento de MS do sorgo na fase de grão leitoso foi superior ao do milho e do sorgo na fase de emborrachamento (Tabela 2). No entanto, o rendimento do milho foi superior ao do sorgo na fase de emborrachamento. Os diferentes rendimentos verificados no sorgo devem-se aos diferentes estádios vegetativos no momento da colheita.

Vale ressaltar que, de maneira geral, as silagens obtidas apresentaram odor agradável e cor variando de verde intenso, como a silagem de sorgo no estádio de emborrachamento, ao mais claro, como o sorgo com grão leitoso, todavia todas indicando tratar-se de material de boa qualidade.

$\mathrm{Na}$ Tabela 4 estão expressos os consumos voluntários das vacas, de acordo com os tratamentos.

Houve superioridade $(\mathrm{P}<0,05)$ no consumo de MS da silagem ( $\mathrm{kg}$ de MS/dia) e da dieta total ( $\mathrm{kg}$ de MS/dia e \% Peso vivo) pelos animais tratados com silagem de milho, em relação àqueles que receberam as silagens de sorgo.

Em trabalhos comparativos entre diversas espécies de milho e sorgo quanto ao consumo de silagens, GOMIDE et al. (1987) e MIAKI et al. (1989) obtiveram resultados s semelhantes aos encontrados nesta

Tabela 3 - Teores de matéria seca (MS), matéria orgânica (MO), proteína bruta (PB), fibra em detergente neutro (FDN) e energia bruta (EB) das silagens de milho (SM), silagem sorgo-emborrachamento (SSE), silagem sorgo-grão leitoso (SSL), palma forrageira (PF) e concentrado

Table 3 - Concentrations of dry matter (DM), organic matter $(\mathrm{OM})$, crude protein (CP), neutral detergent fiber (NDF) and gross, energy of corn silage (CS), sorghum silage in a boot stage (SSB), sorghum silage grain milk (SSM), spineless cactus (SC) and concentrate

\begin{tabular}{|c|c|c|c|c|c|}
\hline $\begin{array}{l}\text { Nutrientes } \\
\text { Nutrients }\end{array}$ & $\begin{array}{l}\mathrm{SM} \\
C S\end{array}$ & $\begin{array}{l}\text { SSE } \\
\text { SSB }\end{array}$ & $\begin{array}{l}\text { SSL } \\
\text { SSM }\end{array}$ & $\begin{array}{l}\mathrm{PF} \\
S C\end{array}$ & $\begin{array}{c}\text { Concentrado } \\
\text { Concentrate }\end{array}$ \\
\hline $\begin{array}{l}\mathrm{MS}(\%) \\
D M(\%)\end{array}$ & 27,39 & 19,77 & 30,19 & 11,68 & 89,81 \\
\hline $\begin{array}{l}\mathrm{MO}(\% \text { da } \mathrm{MS}) \\
O M(\% D M)\end{array}$ & 93,95 & 92,22 & 94,77 & 88,32 & 92,50 \\
\hline $\begin{array}{l}\mathrm{PB}(\% \text { da } \mathrm{MS}) \\
C P(\% D M)\end{array}$ & 6,12 & 6,09 & 3,70 & 4,40 & 19,38 \\
\hline $\begin{array}{l}\mathrm{FDN}(\% \text { da MS }) \\
N D F(\% D M)\end{array}$ & 69,79 & 75,85 & 77,25 & $26,7^{1}$ & $17,26^{2}$ \\
\hline $\begin{array}{l}\text { EB } \\
(\mathrm{kcal} / \mathrm{kg} \text { de MS) } \\
\text { GE (kcal/kg of } D\end{array}$ & $\begin{array}{l}\text { 4305,2 } \\
\text { M) }\end{array}$ & 4221,2 & 4298,2 & 3638,4 & 4513,4 \\
\hline
\end{tabular}

Rev. bras. zootec., 30(6S):2086-2092, 2001 
Tabela 4 - Consumos médios diários de matéria seca das silagens, concentrado e da dieta total e, consumo médio diário de proteína bruta (PB), fibra em detergente neutro (FDN) e energia digestível (ED) de vacas recebendo silagem de milho (SM), silagem de sorgo estádio de emborrachamento ou silagem de sorgo grão leitoso (SSL)

Table 4 - Average daily intake of dry matter from silage, concentrate and total diet, and average daily intake of crude protein (CP), neutral detergent fiber (NDF), digestible energy of cows fed corn silage (CS), sorghum silage boot stage (SSB) or sorghum silage milk (SSM)

\begin{tabular}{lcccc}
\hline & \multicolumn{3}{c}{ Tratamentos } & CV(\%) \\
\cline { 2 - 4 } & Treatments & \\
\cline { 2 - 4 } Itens & SM & SSE & SSL & \\
& $4,93^{\mathrm{a}}$ & $4,20^{\mathrm{b}}$ & $3,69^{\mathrm{b}}$ & 12,98 \\
\hline $\begin{array}{l}\text { Silagem (kg de MS/dia) } \\
\text { Silage (kg DM/day) }\end{array}$ & & & & \\
$\begin{array}{l}\text { Concentrado (kg MS/dia) } \\
\text { Concentrate (kg DM/day) }\end{array}$ & $4,84^{\mathrm{a}}$ & $4,34^{\mathrm{ab}}$ & $4,06^{\mathrm{b}}$ & 14,49 \\
$\begin{array}{l}\text { Palma (kg MS/dia) } \\
\text { Spineless cactus (kg DM day) }\end{array}$ & 2,92 & 2,92 & 2,92 & \\
$\begin{array}{l}\text { Dieta total (kg de MS/dia) } \\
\text { Diet (kg DM/day) }\end{array}$ & $12,66^{\mathrm{a}}$ & $11,43^{\mathrm{b}}$ & $10,68^{\mathrm{b}}$ & 8,56 \\
$\quad(\%$ Peso vivo) & & & & \\
$\quad$ (\% Live weight) & $2,15^{\mathrm{a}}$ & $1,94^{\mathrm{b}}$ & $1,81^{\mathrm{b}}$ & 9,00 \\
$\begin{array}{l}\text { PB (kg/dia) } \\
\text { CP (kg/day) }\end{array}$ & $1,38^{\mathrm{a}}$ & $1,23^{\mathrm{a}}$ & $1,05^{\mathrm{b}}$ & 12,32 \\
$\begin{array}{l}\text { FDN total (kg/dia) } \\
\text { NDF (kg/day) }\end{array}$ & $5,00^{\mathrm{a}}$ & $4,71^{\mathrm{ab}}$ & $4,27^{\mathrm{b}}$ & 13,25 \\
\hline
\end{tabular}

Médias nas linhas, seguidas de letras iguais, não diferem $(P>0,05)$ pelo teste Tukey.

Means in a row, followed by same letters, do not differ $(P>05)$ by Tukey test.

pesquisa. No entanto, PIMENTEL et al. (1997) e PIMENTEL et al. (1998) não encontraram efeito da espécie forrageira sobre o consumo em bovinos.

O estádio de maturidade do sorgo não influenciou significativamente $(\mathrm{P}>0,05)$ o consumo da silagem nem da ração, expressos em $\mathrm{kg}$ de $\mathrm{MS} / \mathrm{dia}$ e $\%$ do peso vivo. Estes dados podem ser justificados pelo fato de não ter havido diferenças $(\mathrm{P}>0,05)$ na ingestão de silagem e concentrado entre os estádios e mesma quantidade de palma.

FERNANDES (1978) e BARROCAS et al. (1981) avaliando diferentes espécies e estádios vegetativos de sorgo para silagem concluíram que os diferentes estádios de maturidade não afetaram o consumo dos animais. No entanto, BROWNING et al. (1967) e ALMEIDA et al. (1995) verificaram que o consumo foi influenciado pelo estádio vegetativo da planta.

O consumo total de FDN variou de 4,27 nos animais recebendo silagem de sorgo fase leitoso, a $5,0 \mathrm{~kg} /$ dia nos animais que consumiram silagem de milho, o que correspondeu a 0,71 e $0,83 \%$ do PV, valores estes inferiores a ingestão de FDN da ordem de $1,2 \%$ do peso vivo, citado por MERTENS (1992) como limitante para o consumo de MS.

De maneira geral, houve déficit nos consumos de MS e PB quando comparados com as exigências do NRC (1988). É possível que nos cercados onde os animais permaneceram a maior parte do tempo, não terem oferecido conforto aos mesmos, provocando assim condições de stress. Também, os componentes que faziam parte da dieta total foram ofertados separadamente, ou seja, em horários diferenciados e não em uma mistura composta podem ter sido fatores que influenciaram diretamente em valores baixos de consumos de silagens. Assim, os animais para atenderem as exigências de energia para produção tiveram que mobilizar parte se suas reservas orgânicas, podendo ser deduzido pela perda de peso verificados nos animais em todas as dietas.

Os resultados médios referentes a produção total de leite e corrigida a $4 \%$ de gordura e teor de gordura do leite são apresentados na Tabela 5 .

As vacas que receberam silagem de milho produziram mais leite $(\mathrm{P}<0,05)$ do que aquelas que consumiram silagem de sorgo leitoso (Tabela 5). No entanto, para os animais que receberam a silagem de sorgo na fase de emborrachamento não foram verificadas diferenças $(\mathrm{P}>0,05)$ das demais. Apesar de ter havido diferença significativa no consumo de MS entre a silagem de milho e a de sorgo na fase de emborrachamento, os valores desta ficaram muito próximos aos da silagem de milho. Além disto, verifica-se semelhança entre os consumos de PB e FDN, entre as duas silagens, o que pode explicar não ter havido diferença na produção de leite.

Avaliando o efeito de diferentes espécies de milho e sorgo na produção de leite, LANCE et al. (1964) e BAXTER et al. (1984) obtiveram os mesmos resultados encontrados nessa pesquisa, enquanto BRANNON et al. (1965) e MIAKI et al. (1990) não encontraram diferença $(\mathrm{P}>0,05)$ na produção de leite.

Observa-se que o estádio de maturidade não interferiu significativamente $(\mathrm{P}>0,05)$ na produção de leite total e corrigida a $4 \%$ de gordura. Provavelmente, por não ter havido diferença $(\mathrm{P}>0,05)$ em todos os consumos, exceto o da PB, entre as duas silagens. Resultados semelhantes foram obtidos por BROWNING et al. (1967) e BAXTER et al. (1984) quando comparavam silagem de sorgo em diferentes estádios de maturidade.

Não foram observadas diferenças significativas $(\mathrm{P}>0,05)$ no teor de gordura do leite em todas as silagens

Rev. bras. zootec., 30(6S):2086-2092, 2001 
Tabela 5 - Produção média diária e porcentagem de gordura do leite de vacas recebendo silagem de milho (SM), silagem de sorgo estádio de emborrachamento (SSE) ou silagem de sorgo grão leitoso (SSL)

Table 5 - Average daily milk production and milk fat percent of cows fed corn silage (CS), sorghum silage boot stage (SSB) or sorghum silage milk (SSM)

\begin{tabular}{ccccc}
\hline SM & SSE & SSL & CV(\%) \\
$C S$ & $S S B$ & SSM & \\
\hline
\end{tabular}

Produção de leite

Milk production

Total $(\mathrm{kg} / \mathrm{dia})$

Total ( $\mathrm{kg} /$ day)

$15,23^{\mathrm{a}} \quad 14,28^{\mathrm{ab}} \quad 12,55^{\mathrm{b}} \quad 16,00$

Corrigida

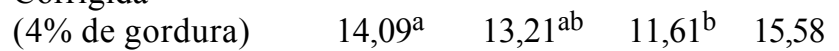

Corrected (4\% fat)

Gordura no leite $(\%) \quad 3,55^{\mathrm{a}} \quad 3,43^{\mathrm{a}} \quad 3,62^{\mathrm{a}} \quad 7,33$

Milk fat (\%)

Médias nas linhas, seguidas de letras iguais, não diferem $(P>0,05)$ pelo teste Tukey.

Means in a row, followed by same letters, do not differ $(P>.05)$ by Tukey test.

avaliadas, concordando com os resultados encontrados por BROWNING et al. (1961) e MIAKI et al. (1990).

Vale ressaltar que, apesar da superioridade da silagem de milho na produção de leite em relação a silagem de sorgo no estádio de grão leitoso, essa obteve um maior rendimento de MS/ha quando comparado ao milho. Deve-se considerar ainda que o sorgo é uma cultura mais adaptada as condições climáticas do semi-árido.

De modo geral, o estádio de maturidade do sorgo não interferiu no consumo, na produção e no teor de gordura do leite e o rendimento de MS/ha foi maior no estádio mais avançado de maturidade. Isto nos leva a concluir que não justificou colher o sorgo no estádio de emborrachamento, apesar de, nas condições do semi-árido, em algumas situações, essa colheita ser economicamente viável.

\section{Conclusões}

A silagem de milho propiciou maior consumo de matéria seca na forma de silagem e de dieta total, quando comparada às silagens de sorgo.

Os animais alimentados com silagem de milho produziram mais leite, quando comparados aos que receberam silagem de sorgo no estádio de grão leitoso.

O estádio de maturidade do sorgo não interferiu no consumo, na produção e teor de gordura do leite.

\section{Agradecimento}

Ao Conselho Nacional de Desenvolvimento Científico e Tecnológico (CNPq), pela concessão de bolsa de estudos.

\section{Referências Bibliográficas}

ALMEIDA, M.F., TIESENHAUSEN, I.M.E.V.V., AQUINO, L.H. et al. 1995. Composição química e consumo voluntário das silagens de sorgo, em dois estádios de corte, girassol e milho para ruminantes. R. Ciência Prática, 19(3):315-321.

BARROCAS, F.A.L., SOUZA, A.A. Influência do estádio de maturação sobre o consumo voluntário e digestibilidade de silagem de sorgo In: REUNIÃO ANUAL DA SOCIEDADE BRASILEIRA DE ZOOTECNIA, 18, 1981, Goiânia. Anais... Goiânia: SBZ, 1981. p.338.

BAXTER, H.D., MONTGOMERY, M.J., OWEN, J.R. 1984. Comparison of soybean-grain sorghum silage with corn silage for lactating cows. J. Dairy Sci., 67(1):88-96.

BEHMER, M.L.A. 1965. Lacticinios, leite, manteiga, queijo, caseína e instalações. 3.ed. São Paulo: Melhoramento. 294p.

BISHNOI, U.R., OKA, G.M., FEARON, A.L. 1993. Quantity and quality of forage and silage of pearl millet in comparison to sudax, grain, and forage sorghums harvested at different growth stages. Trop. Agric., 70(2):98-102.

BRANNON, C.C, KING, W.A., COOK, W.C. 1965. Sorghum silage for milking cows. J. Dairy Sci., 48(6):838.

BROWNING, C.B., LUSK, J.W. 1967. Effect of stage of maturity at harvest on nutritive value of combine-type grain sorghum silage. J. Dairy Sci., 50(1):81-85.

CRAMPTON, E.W. 1957. Interrelations between digestible nutrient and energy content, voluntary dry matter, intake and the overall. J. Anim. Sci., 16(3):546-552.

CHAVES, A.V., OLIVEIRA, J.S., ROCHA, V.S. et al. Comparação de cultivares de sorgo (Sorghum bicolor L. Moench) para produção de silagem. In: REUNIÃO ANUAL DA SOCIEDADE BRASILEIRA DE ZOOTECNIA, 34., 1997, Juiz de Fora. Anais... Juiz de Fora: SBZ, 1997. p.193-195.

DIAS, J.C., COSTA, J.L. 1997. Forragens para o gado leiteiro. São Paulo: Tortuga/Juiz de Fora: Embrapa - CNPGL. 98p.

EMPRESA PERNAMBUCANADEPESQUISA AGROPECUÁRIA - IPA. 1993. Cultivo do sorgo. Recife, PE. 4p. (Instruções técnicas, 34).

FERNANDES, W. Produtividade do sorgo "Santa Liza" (Sorghum vulgare, Pers) em seis idades e valor nutritivo das silagens. Viçosa, MG: UFV, 1978. 64p. Dissertação (Mestrado em Zootecnia) Universidade Federal de Viçosa, 1978.

GENRO, T.C.M., QUADROS, F.L.F., COELHO, L.G.M. et al. 1995 Produção e qualidade de silagens de híbridos de milho (Zea mays) e de híbridos de sorgo (Sorghum bicolor). R. Ciência Rural, 25(3):461-464.

GOMIDE, J.A., ZAGO, C.P., CRUZ, M.E. et al. 1987. Milho e sorgo em cultivos puros ou consorciados com soja, para produção de silagens. R. Bras. Zootec., 16(4):308-317. 
LANCE, R.D., FOSS, D.C., KRUEGER, C.R. et al. 1964. Evaluation of corn and sorghum silages on the basis of milk production and digestibility. J. Dairy Sci., 47(3):254-257.

LAVEZZO, W. Conservação de forragem In: SIMPÓSIO NORDESTINO DE ALIMENTAÇÃO DE RUMINANTES, 2., 1988, Natal. Anais... Natal: ENPARN, 1988. p.29-80.

MERTENS, D.R. Análise da fibra e sua utilização na avaliação de alimentos e formulação de rações.In: REUNIÃO ANUAL DA SOCIEDADE BRASILEIRA DE ZOOTECNIA, 29., 1992, Lavras. Anais... Lavras: SBZ, 1992. p.188-217.

MIAKI, T., TANAKA, S., KAWAMURA, O. et al. 1989. Comparison of feeding value between corn silage and sorghum silage for lactating cows. J. Zootec. Sci., 2(60):127-132.

MIAKI, T., TANAKA, S., KAWAMURA, O. et al. 1990. Comparison of feeding value of sorghum, pearl-millet and corn silages on the basis of milk production. J. Zootec. Sci., 2(36):361-366.

NATIONAL RESEARCH COUNCIL - NRC. 1988. Nutrient requirements of dairy cattle. 6.ed. Washington, D.C. 157p.

PIMENTEL, J.J.O., SILVA, J.F.C., VALADARES FILHO, S.C. et al. Efeito da suplementação protéica no valor nutritivo de silagens de milho e de sorgo. In: REUNIÃO ANUAL DA SOCIEDADE BRASILEIRA DE ZOOTECNIA, 34., 1997, Juiz de Fora. Anais... Juiz de Fora: SBZ, 1997. p.184-186.

PIMENTEL, J.J.O., SILVA, J.F.C., VALADARES FILHO, S.C. et al. 1998. Efeito da suplementação protéica no valor nutritivo da silagem de milho e sorgo. R. Bras. Zootec., 27(5):1042-1049.

RODRIGUES, J.A.S., SILVA, F.E., GONÇALVES, L.C. Silagem de diferentes cultivares de sorgo forrageiro colhidos em diversos estádios de desenvolvimento. In: CONGRESSO NACIONAL DE MILHO E SORGO, 21., 1996, Londrina. Resumos... Londrina: LAPAR, 1996. p.269.

RUGGIERI, A.C., TONANI, F., GUIM, A. et al. Efeito do estágio de maturação sobre a composição bromatológica da planta e da silagem de três híbridos de sorgo (Sorghum bicolor, L.). In: REUNIÃO ANUAL DA SOCIEDADE BRASILEIRA DE ZOOTECNIA, 32, 1995, Brasília. Anais... Brasília: SBZ, 1995. p.107-108.
SAMPAIO, I.B.M. 1998. Estatística aplicada à experimentação animal. 1.ed. Belo Horizonte: Fundação de Ensino e Pesquisa em Medicina Veterinária e Zootecnia. 221p.

SILVA, D.J. 1990. Análise de alimentos: métodos químicos e biológicos. 2.ed. Viçosa: UFV. 166p.

TEIXEIRA, J.C. 1992. Nutrição de ruminantes. Lavras: FAEPE, $239 \mathrm{p}$.

VALENTE, J.O., SILVA, J.F.C., GOMIDE, J.A. 1984. Estudo de duas variedades de milho (Zea mays L.) e de quatro variedades de sorgo (Sorghum bicolor $L$ Moench) para silagem. 2. Valor nutritivo e produtividade das silagens. R. Bras. Zootec., 13(13):74-81.

VALENTE, J.O. Produtividade de duas variedades de milho (Zea mays L.) e de quatro variedades de sorgo (Sorghum bicolor (L) Moench) e valor nitritivo de suas silagens. Viçosa, MG:UFV,1977.76p. Dissertação (Mestrado em Zootecnia) - Universidade Federal de Viçosa, 1977.

VILELA, D. 1985. Sistemas de conservação de forragem. 1. Silagem. Coronel Pacheco: EMBRAPA-CNPGL. p.42. (Boletim de Pesquisa, 11).

Recebido em: 06/06/00

Aceito em: 13/08/01 